\title{
Ground settlement prediction of embankment treated with prefabricated vertical drains in soft soil
}

\author{
Siswoko Adi Saputro ${ }^{1,2}$, Agus Setyo Muntohar ${ }^{1, *}$, and Hung Jiun Liao ${ }^{2}$ \\ ${ }^{1}$ Department of Civil Engineering, Universitas Muhammadiyah Yogyakarta, Yogyakarta, Indonesia \\ ${ }^{2}$ Department of Civil and Construction Engineering, National Taiwan University of Science and \\ Technology, Taipei, Taiwan
}

\begin{abstract}
Excessive settlement due to consolidation can cause damage to the structure's rest on soft soil. The settlement takes place in relatively longer. The preloading and prefabricated vertical drain (PVD) is often applied to accelerate the primary settlement. The issue in this research is the estimation of the settlement. The Asaoka method and the finite element method using PLAXIS-2D are used to estimate the final settlement of a PVD treated embankment. For the former, a complete record of the settlement was required; for the latter, some ground parameters are needed for the PLAXIS-2D analysis, such as the permeability of the soil. Because the installation process of PVD tends to influence the permeability of the in-situ soil around the PVD, the soil permeability after the installation of PVD needs to be adjusted. The numerical results were compared with actual settlement data to find out the best-fit input parameters (i.e. soil permeability) of the actual data. It was found that the best-fit soil permeability (k) used in the numerical study was about one-half of the $\mathrm{k}$ value determined from the laboratory test. The Root Mean Square Deviation shows that the settlement predicted by the numerical analysis has approximately $30 \%$ of the actual settlement.
\end{abstract}

Keywords: settlement, consolidation, PVD, Asaoka method, PLAXIS-2D, soil permeability

\section{Introduction}

The ground settlement due to consolidation is often experienced in the construction work on soft soil. Soft clay tends to decrease prolonged and persistent time. Soil improvement methods with preloading and prefabricated vertical drain (PVD) are often used in work to accelerate the consolidation as applied at Suvarnabhumi Airport Project in Thailand [1]. However, excessive ground settlement can induce damage to the structure above the soil.

One of the problems in the work of soil improvement methods with preloading and prefabricated vertical drain (PVD) is to determine the magnitude and duration of the final settlement until the spoil reach the minimum pore water pressure. The Terzhagi theory is

*Corresponding author: muntohar@umy.ac.id 
commonly adopted to predict the magnitude of ground settlement. However, on the reality, the stress-strain relationship of the soil is very complicated to estimate, where the soil is anisotropic, heterogeneous and non-elastic, so multi-dimensional analysis is necessary. The method that can be used to analyze multi-dimensional finite element method (FEM). The modelling of the embankment with the FEM method is quite complicated to do because the accuracy of the results depends on the complete field data and precisely the assumptions on soil conditions in the field $[2,3,4]$. Asaoka Observation Method (Asaoka Method) can also be used to predict the amount of final ground settlement (final settlement) instead of the Terzhagi and numerical methods. In the Asaoka Method, the magnitude of actual ground settlement can be predicted without the parameters used in the consolidation analysis, such as pore water pressure data, drainage length, maximum soil strain and consolidation coefficient. However, the method needs a complete field measurement $[5,6]$. The field data are deriving and analyzed by curve fitting (see Fig. 1).
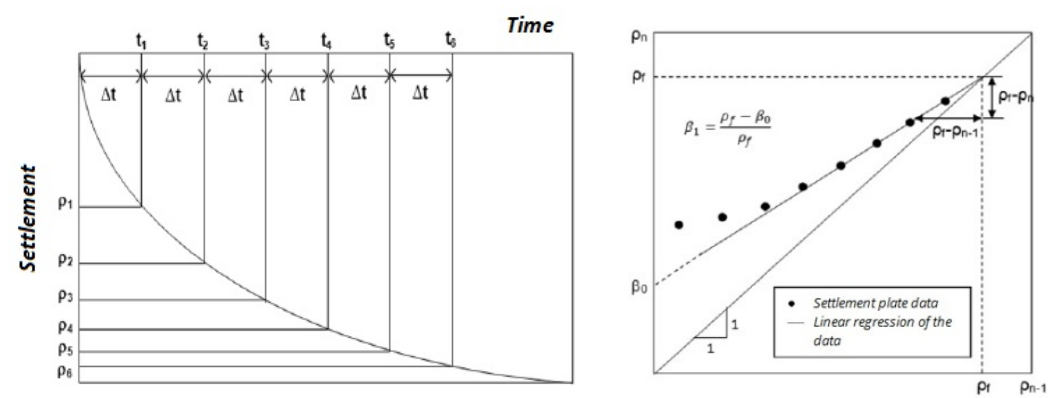

Fig. 1. (a) Monitored settlement and analysis procedure with a constant time interval, (b) Final ground settlement prediction based on field measurement data [5].

In this study, the case report of Achmad Yani Airport project was used to evaluate the effectiveness of the Asaoka Method for predicting the final ground settlement of the PVD-improved the soft soil. The ground settlement was also numerically modelled using PLAXIS 2D finite element method (FEM). The numerical model was performed to investigate the effect of coefficient of permeability on the settlement behavior of the improved soft soil with PVD. This paper is aiming to determine the approximate method for modelling a real field condition.

\subsection{Geotechnical site condition}

The expansion project of Ahmad Yani airport, Semarang, Central Java 2012-2013 was on the alluvial soil deposit where is located near the Java Sea at the north of Semarang. The geotechnical exploration was conducted to determine the soil properties and subsurface condition. The locations of soil investigation are shown in Fig. 2. Based on the investigation and laboratory tests, four main soil layers (very soft, soft, stiff and very stiff) were found underlying the site. The soft clay layer on top has a thickness of 25-30 m. The soils were classified as $\mathrm{CH}$ according to USCS classification. Fig. 3 shows the soil profile established from BM-03 to BM-04. The SPT-N data from borehole BM-03 and BM-04 were chosen for this study because the large settlement was found from the nearby settlement plates at SP-13, SP-14 and SP-15. Tables 1 and 2 summarize the soil properties of in-situ soil as well as the preloading soil. 


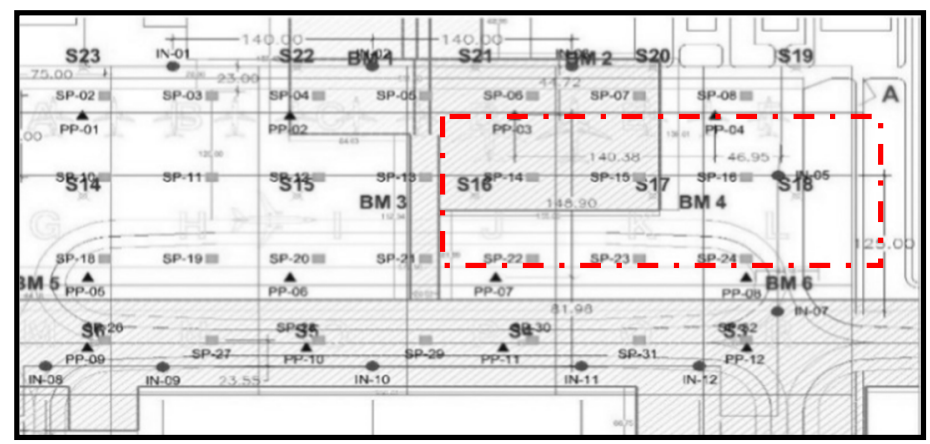

Fig. 2. The plan of geotechnical investigation.

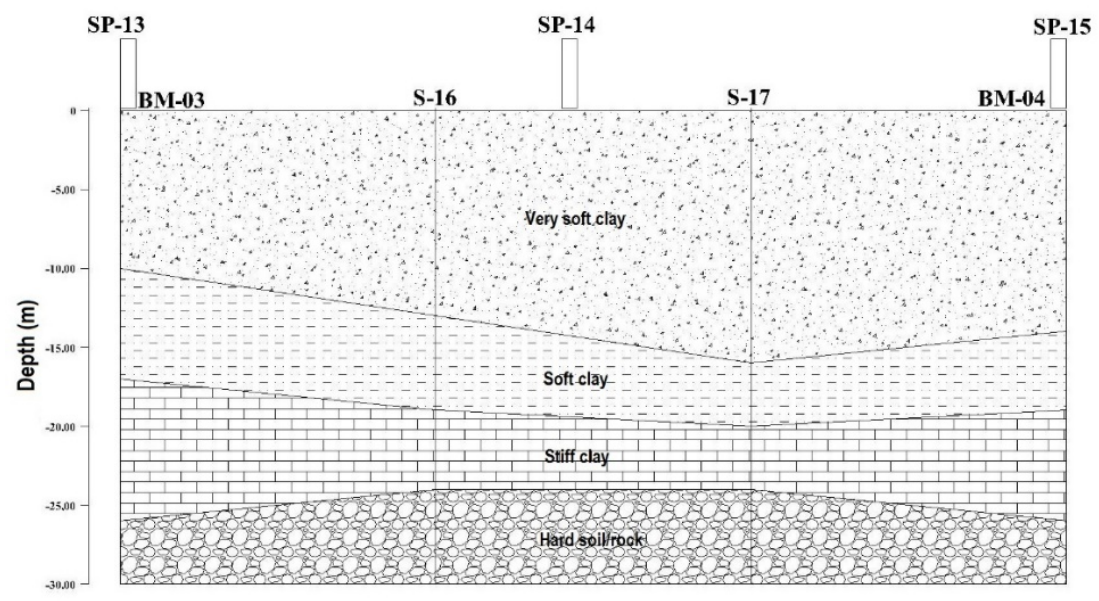

Fig. 3. The Soil profile at the A-A cross section (refer to Fig.2).

\subsection{Ground improvement}

The preloading combined with prefabricated vertical drain (PVD) method was used in this construction site to speed up the consolidation rate of the soft clayey soil. Geotextile was also used to improve the soil shear strength on the preloading process. The geotextile used was type TW-200 with EA $21 \mathrm{kN} / \mathrm{m}$. Piezometers were installed at a depth of 6, 12 and 18 meters to monitor the change of pore water pressure during the consolidation process. The PVD dimension is $100 \mathrm{~mm} \times 4 \mathrm{~mm}$, and $20 \mathrm{~m}$ length. The spacing was arranged in a triangular layout by 1.2-meter center to center. The cross-section profile of embankment and instrumentation is shown in Fig. 4. 
Table 1. Laboratory test result for boreholes BM-03 and BM-04.

\begin{tabular}{|c|c|c|c|c|c|c|c|c|c|}
\hline $\begin{array}{c}\text { Bore } \\
\text { hole }\end{array}$ & $\begin{array}{c}\text { Depth } \\
(\mathbf{m})\end{array}$ & $\begin{array}{c}\text { Soil } \\
\text { type }\end{array}$ & $\begin{array}{c}\gamma_{\mathbf{s}} \\
\left(\mathbf{k N} / \mathbf{m}^{\mathbf{3}}\right)\end{array}$ & $\begin{array}{c}\gamma_{\mathbf{d}} \\
\left(\mathbf{k N} / \mathbf{m}^{\mathbf{3}}\right)\end{array}$ & $\mathbf{e}$ & $\mathbf{C}_{\mathbf{c}}$ & $\mathbf{C}_{\mathbf{s}}$ & $\mathbf{k}_{\mathbf{v}}(\mathbf{m} / \mathbf{d a y})$ & $\boldsymbol{\phi}(\mathbf{})$ \\
\hline \multirow{4}{*}{$\begin{array}{c}\text { BM- } \\
03\end{array}$} & $2.5-3.0$ & $\mathrm{CH}$ & 15.59 & 8.63 & 2.02 & 1.08 & 0.069 & $1.62 \times 10^{-3}$ & 12.0 \\
\cline { 2 - 10 } & $5.5-6.0$ & $\mathrm{CH}$ & 14.91 & 7.46 & 2.45 & 1.67 & 0.079 & $0.18 \times 10^{-3}$ & 1.77 \\
\cline { 2 - 10 } & $8.5-9.0$ & $\mathrm{CH}$ & 14.81 & 8.24 & 1.72 & 0.94 & 0.063 & $1.60 \times 10^{-3}$ & 9.17 \\
\cline { 2 - 10 } & $11.5-12.0$ & $\mathrm{CH}$ & 14.22 & 7.26 & 2.52 & 5.76 & 0.283 & $0.89 \times 10^{-3}$ & 5.29 \\
\cline { 2 - 10 } & $14.5-15.0$ & $\mathrm{CH}$ & 14.81 & 7.95 & 1.93 & 1.40 & 0.067 & $0.84 \times 10^{-3}$ & 7.04 \\
\cline { 2 - 10 } & $17.5-18.0$ & $\mathrm{CH}$ & 23.25 & 16.58 & 0.57 & 0.66 & 0.036 & $7.45 \times 10^{-3}$ & 6.40 \\
\hline \multirow{4}{*}{$\mathrm{BM}-$} & $2.5-3.0$ & $\mathrm{CH}$ & 16.58 & 9.52 & 1.52 & 1.10 & 0.058 & $1.33 \times 10^{-3}$ & 7.12 \\
\cline { 2 - 10 } 04 & $5.5-6.0$ & $\mathrm{CH}$ & 18.84 & 11.18 & 1.28 & 0.95 & 0.052 & $1.37 \times 10^{-3}$ & 9.55 \\
\cline { 2 - 10 } & $8.5-9.0$ & $\mathrm{CH}$ & 12.65 & 7.75 & 1.88 & 1.05 & 0.066 & $1.18 \times 10^{-3}$ & 4.70 \\
\cline { 2 - 10 } & $11.5-12.0$ & $\mathrm{CH}$ & 15.89 & 8.44 & 2.06 & 5.60 & 0.281 & $6.75 \times 10^{-3}$ & 6.38 \\
\cline { 2 - 10 } & $14.5-15.0$ & $\mathrm{CH}$ & 15.30 & 7.95 & 2.17 & 1.52 & 0.073 & $1.13 \times 10^{-3}$ & 12.1 \\
\cline { 2 - 10 } & $17.5-18.0$ & $\mathrm{CH}$ & 14.91 & 9.03 & 1.76 & 1.00 & 0.063 & $1.79 \times 10^{-3}$ & 3.53 \\
\hline
\end{tabular}

Table 2. The properties of embankment fill.

\begin{tabular}{|c|c|c|c|c|c|c|c|c|}
\hline $\begin{array}{c}\text { SPT- } \\
\mathbf{N}\end{array}$ & $\mathrm{E}(\mathrm{kPa})$ & $\begin{array}{c}\gamma_{\mathrm{un}} \\
\left(\mathrm{kN} / \mathrm{m}^{3}\right)\end{array}$ & $\begin{array}{c}\gamma_{\mathrm{sat}} \\
\left(\mathbf{k N} / \mathrm{m}^{3}\right)\end{array}$ & $\begin{array}{c}\mathrm{c} \\
(\mathrm{kPa})\end{array}$ & $\phi\left(\left(^{0}\right)\right.$ & $\mathbf{k}_{\text {sat }}$ (m/day) & $v$ & einit \\
\hline 11 & 10,000 & 16 & 19 & 5 & 25 & 0.043 & 0.3 & 1.1 \\
\hline
\end{tabular}

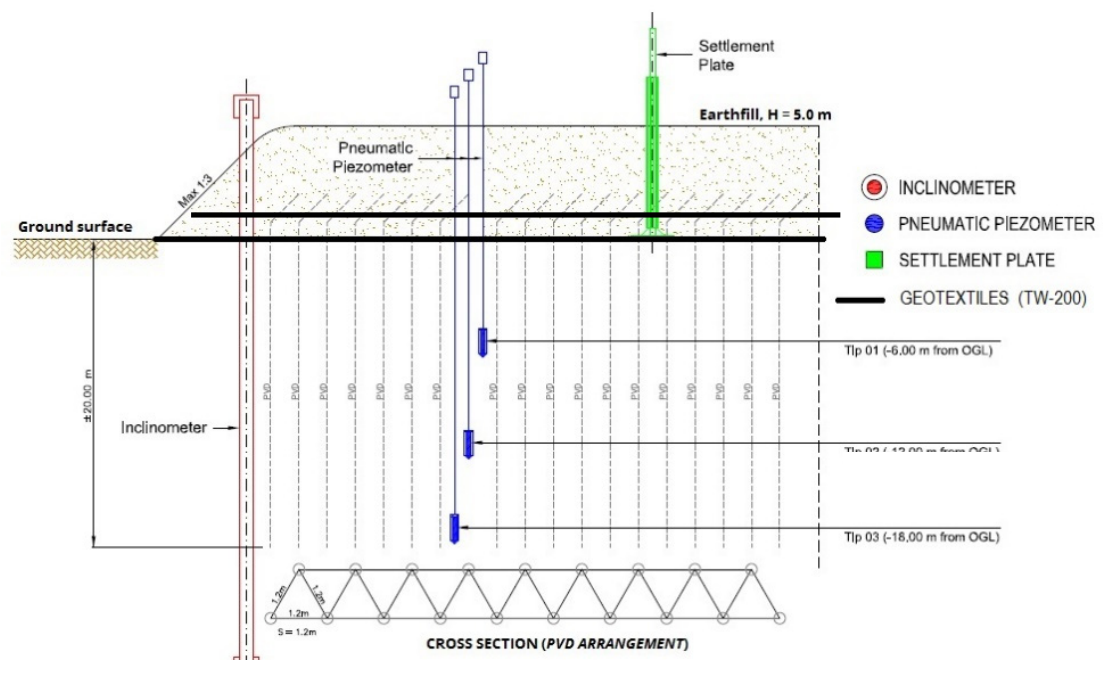

Fig. 4. The profile of embankment, PVDs, and instrumentation setting. 


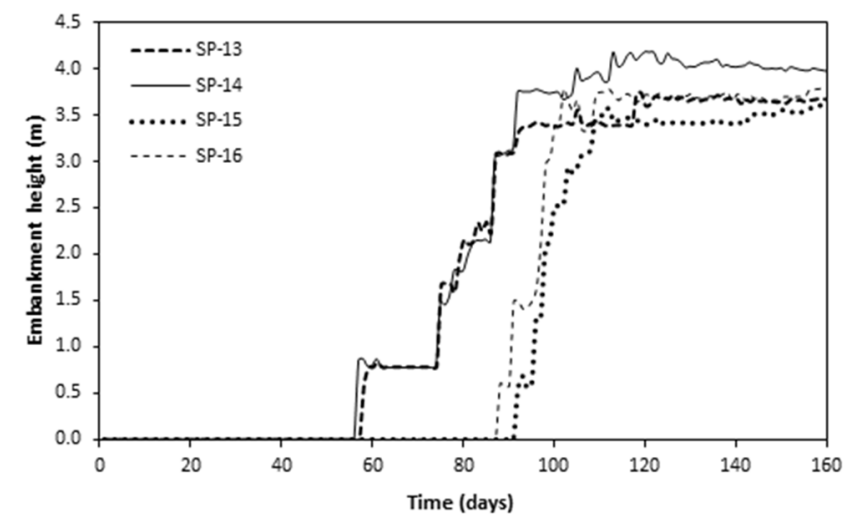

Fig. 5. Stage construction of embankment.

\subsection{Construction stage}

Stage of embankment construction is an essential input parameter in the calculation of final settlement using Asaoka Method and the finite element model. The relationship between the construction time and height of the embankment is shown in Fig. 5. The highest embankment was designed about $4 \mathrm{~m}$.

\section{Numerical modelling}

\subsection{Soil properties}

Numerical modelling was conducted using finite element method (PLAXIS 2D). In this analysis, the soil layer was divided into several layers based on soil profile. The soft soil is modelled using a modified Cam-clay model, while the Mohr-Coulomb model is used to analyse the preloading soil. The modified Cam-clay is suitable to analyse the consolidation behaviour of clayey soil [7]. The modified Cam-clay model needed the parameters including the modified compression index $(\lambda)$ and modified swelling index $(\kappa)$, which can be obtained from the Equation 1 and 2 respectively.

$$
\begin{aligned}
& \lambda=\frac{C_{c}}{2.3\left(1+e_{o}\right)} \\
& \kappa=\frac{2 C_{s}}{2.3\left(1+e_{o}\right)}
\end{aligned}
$$

where $C_{c}$ is compression index, $C_{s}$ is swelling index, and $e_{o}$ is initial void ratio. Table 3 and 4 respectively show the soil parameters used in the numerical modelling for both the in-situ and preloading soils.

In this finite element analysis, the coefficient of permeability was varied and represented as permeability ratio between numerically-coefficient of permeability $\left(k_{v e}\right)$ and laboratory-coefficient of permeability $\left(k_{y}\right)$. The ratio $k_{v e} / k_{y}$ ranges from 0.1 to 2 . This range was determined to obtain a realistic coefficient of permeability that results in a closer 
settlement behaviour to the field measurement.

Table 3. Soft soil parameters for the modified Cam-clay model in the numerical analysis.

\begin{tabular}{|c|c|c|c|c|c|c|c|c|}
\hline Borehole & Depth $(\mathbf{m})$ & Soil type & $\boldsymbol{M}$ & $\boldsymbol{\lambda}$ & $\boldsymbol{\kappa}$ & $\boldsymbol{v}$ & $\boldsymbol{e}_{\boldsymbol{0}}$ & $\mathbf{c}(\mathbf{k P a})$ \\
\hline \multirow{5}{*}{ BM-03 } & $2.5-3.0$ & Very Soft & 1.2 & 0.16 & 0.01 & 0.3 & 2.02 & 6.3 \\
\cline { 2 - 9 } & $5.5-6.0$ & Very Soft & 1.2 & 0.21 & 0.02 & 0.3 & 2.45 & - \\
\cline { 2 - 9 } & $8.5-9.0$ & Very Soft & 1.2 & 0.15 & 0.01 & 0.3 & 1.72 & 3.2 \\
\cline { 2 - 9 } & $11.5-12.0$ & Soft & 1.2 & 0.71 & 0.07 & 0.3 & 2.52 & - \\
\cline { 2 - 9 } & $14.5-15.0$ & Medium & 1.18 & 0.21 & 0.02 & 0.3 & 1.93 & - \\
\cline { 2 - 9 } & $17.5-30.0$ & Very Stiff & 1.08 & 0.18 & 0.02 & 0.3 & 0.57 & 20.5 \\
\hline \multirow{5}{*}{ BM-04 } & $2.5-3.0$ & Very Soft & 1.2 & 0.19 & 0.02 & 0.3 & 1.52 & 4.8 \\
\cline { 2 - 9 } & $5.5-6.0$ & Very Soft & 1.2 & 0.18 & 0.02 & 0.3 & 1.28 & 4.4 \\
\cline { 2 - 9 } & $8.5-9.0$ & Very Soft & 1.2 & 0.16 & 0.01 & 0.3 & 1.88 & - \\
\cline { 2 - 9 } & $11.5-12.0$ & Soft & 1.2 & 0.80 & 0.08 & 0.3 & 2.06 & 1.2 \\
\cline { 2 - 9 } & $14.5-15.0$ & Medium & 1.18 & 0.21 & 0.02 & 0.3 & 2.17 & 3.8 \\
\cline { 2 - 8 } & $17.5-30.0$ & Very Stiff & 1.08 & 0.16 & 0.01 & 0.3 & 1.76 & - \\
\hline
\end{tabular}

Table 4. Embankment soil parameters f6or Mohr-Coulomb model in the numerical analysis.

\begin{tabular}{|c|c|c|c|c|c|}
\hline $\mathbf{E}(\mathbf{k P a})$ & $\gamma_{\text {un }}\left(\mathbf{k N} / \mathbf{m}^{\mathbf{3}}\right)$ & $\gamma_{\text {sat }}\left(\mathbf{k N} / \mathbf{m}^{\mathbf{3}}\right)$ & $\mathbf{c}(\mathbf{k P a})$ & $\boldsymbol{\phi}\left(^{\mathbf{0}}\right)$ & $\boldsymbol{v}$ \\
\hline 10000 & 16 & 19 & 5 & 25 & 0.3 \\
\hline
\end{tabular}

\subsection{PVD properties}

The PVD is modelled with a drain element of zero thickness [8]. The plane strain model of PVD, which is rectangular, needs to be converted to an equivalent cylinder shape. The diameter of the influence zone $\left(D_{e}\right)$ and the equivalent diameter $\left(d_{w}\right)$ of PVD are shown in Fig. 6. The diameter of the influence zone $\left(D_{e}\right)$ of triangularly laid out PVD can be obtained by the Equation 3 [8]:

$$
D_{e}=1.05 S
$$

where $S$ is PVD spacing.
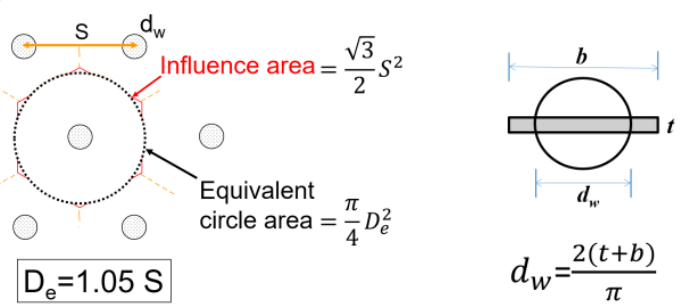

Fig. 6. Illustration of the equivalency concept of PVD diameter and drain zone $[2,8]$.

The installation of PVD will influence the soil permeability as shown in Fig. 7. According to Russel [4], the spacing of PVD also needs to be converted to plane strain condition as given in Equation 4.

$$
B=R \sqrt{\frac{3}{2}\left(\ln (n)-\frac{3}{4}\right)}
$$


where $n=D_{e} / d_{w}$, and $R$ is the unit radius of PVD $\left(=0.5 D_{e}\right)$. Table 5 shows the summary of PVD parameters used in the numerical model.

Table 5. PVD parameters for numerical modelling.

\begin{tabular}{|l|l|c|}
\hline Parameter & Symbol & Value \\
\hline Diameter of drain $(\mathrm{mm})$ & $\mathrm{d}_{\mathrm{w}}$ & 70 \\
\hline Diameter of cell unit & $\mathrm{D}_{\mathrm{e}}$ & 1.26 \\
\hline $\mathrm{D}_{\mathrm{e}} / \mathrm{d}_{\mathrm{w}}$ & $\mathrm{n}$ & 18 \\
\hline Diameter of cell unit (plane strain) & $\mathrm{B}$ & 1.13 \\
\hline Diameter of smear zone & $\mathrm{d}_{\mathrm{s}}$ & - \\
\hline Ratio of kh over $\mathrm{ks}_{\mathrm{s}}$ in field & $\left(\mathrm{k}_{\mathrm{h}} / \mathrm{k}_{\mathrm{s}}\right)$ & - \\
\hline $\mathrm{d}_{\mathrm{s}} / \mathrm{d}_{\mathrm{w}}$ & $\mathrm{s}$ & - \\
\hline
\end{tabular}

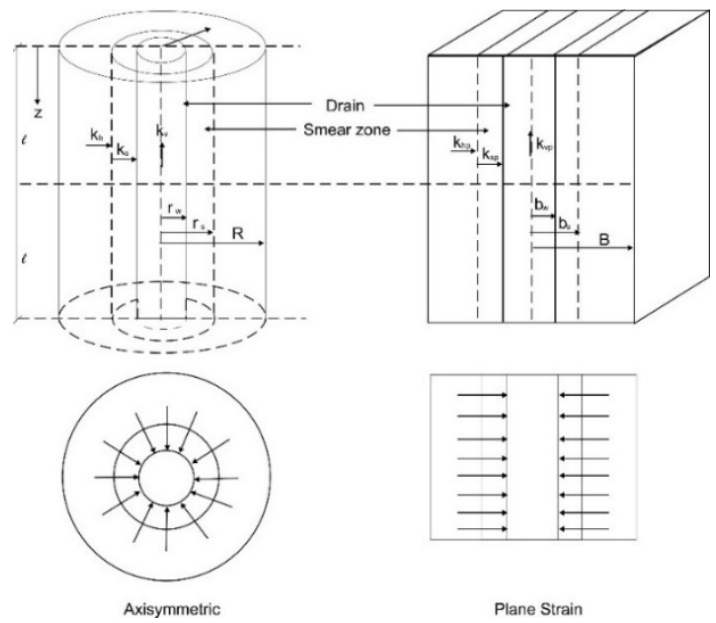

Fig. 7. Illustration of smear zone around the drain $[3,8]$.

\subsection{Ground settlement analysis using Asaoka method}

The graphical method is adopted to analyze final ground settlement in Asaoka method. The ground settlement data was measured with settlement plates at a constant time interval $\Delta t$ and the settlement data of $\rho_{1}, \rho_{2}, \rho_{3}, \ldots, \rho_{\mathrm{n}}$ is recorded and shown in Fig. 1a. Afterward, the settlement data of $\rho_{\mathrm{n}}$ (y-axis) and $\rho_{\mathrm{n}-1}$ (x-axis) were plotted to get the linear regression line of the settlement plate data. The final settlement $\left(\rho_{\mathrm{f}}\right)$ is the intersection point between $45^{\circ}$ of the angle line of $\rho_{n}=\rho_{n-1}$ and actual curve of $\rho_{n}$ vs $\rho_{n-1}$ (see Fig. 1b).

\section{Result and discussion}

\subsection{Final settlement predicted by Asaoka method}

Based on the field measurement data from settlement plates at SP-13, SP-14 and SP-15, Fig. 8 plot the graphical of Asaoka method. Table 6 presents the result of the final settlement and the comparison to the field measurement. All estimated settlement values exceed about $1 \%$ of the field measured data. This result indicates that the Asaoka method shows a reasonable prediction of the final settlement, but the method cannot provide the settlement 
behavior at the early time of construction. Furthermore, Nawir et al. [6] recommended that a carefully recorded observational data is essential to estimate the final settlement accurately. However, the problem of Asaoka method can be compensated by numerical method. By trial and error approach, the numerical model can be used to calculate the final settlement using different soil permeability ratios and calibrate the parameters.

Table 6. Ratio of Asaoka method predicted final settlement and the field measured settlement.

\begin{tabular}{|c|c|c|c|c|}
\hline $\begin{array}{c}\text { Borehole } \\
\text { No. }\end{array}$ & SP No. & $\begin{array}{c}\text { Settlement prediction, } \boldsymbol{\rho}_{\boldsymbol{f}} \\
(\mathbf{m m})\end{array}$ & $\begin{array}{c}\text { Field measurement, } \boldsymbol{S}_{\boldsymbol{f}} \\
(\mathbf{m m})\end{array}$ & $\boldsymbol{\rho}_{\boldsymbol{f}} / \boldsymbol{S}_{\boldsymbol{f}}$ \\
\hline \multirow{2}{*}{ BM-03 } & SP-13 & 1654 & 1637 & 1.010 \\
\cline { 2 - 5 } & SP-14 & 1885 & 1860 & 1.013 \\
\hline BM-04 & SP-15 & 1710 & 1701 & 1.005 \\
\hline
\end{tabular}

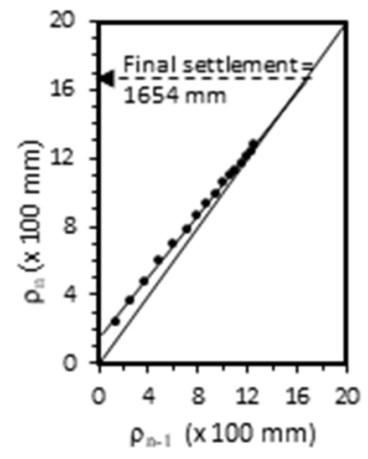

(a)

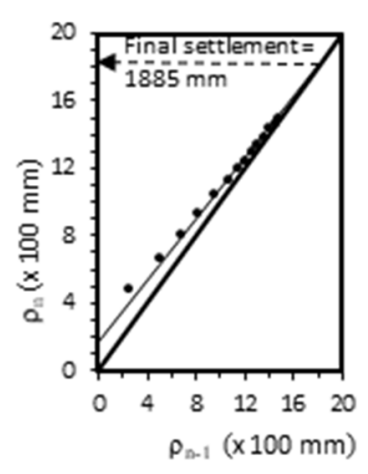

(b)

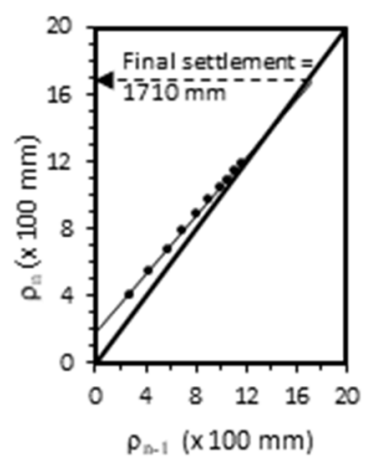

(c)

Fig. 8. Final ground settlements estimated by Asaoka method for (a) SP-13, (b) SP-14 (c) SP-15.

\subsection{Ground settlement behavior}

The variation of the measured ground settlement (field monitoring) with elapsed time at the BM-03 and BM-04 are illustrated in Fig. 9. The figure also presents the settlement obtained from finite element analysis for the various permeability ratio. The figures show that the simulated ground settlement behavior results in a closer behavior to the field measurement if the permeability ratio is equal to $0.5\left(\mathrm{k}_{\mathrm{ve}} / \mathrm{k}_{\mathrm{v}}=0.5\right)$ for all settlement plate location (SP-13 to SP-15). At location SP-14 (Fig. 9b), the calculated ground settlement behavior was found to be close to the field measurement when the permeability ratio was equal to 0.5 . However, the input soil parameters are from BM-04 instead of the BM-03. The behavior indicated that the soil parameters at location SP-14 are closer to those of BM-04 than the BM-03 (refer to Figs.1 and 2). The heterogeneity properties of the soil layer were attributable to a significant difference in the numerical results for this modelling. Therefore, the soil parameters must be adjusted carefully. Similar results were obtained from other modelling at location SP-15 with the BM-04 soil parameters as shown in Fig. 9c.

Table 7 presents the final ground settlement obtained from the finite element analysis. In general, for the observed points, the simulated final settlement is slightly higher than field measurement, except at SP-13. Comparing the prediction results with the Asaoka Method, the Asaoka Method provides a better estimation of the final ground settlement. However, the finite element analysis method can be used to compensate for the problem of Asaoka method to present the settlement behavior with the elapsed time especially at the earlier stage. The Root Mean Square Deviation (RMSD) is used to analyze the percentage 
error of the prediction of the settlement as shown in Fig. 10. It can be seen in Fig. 10 that the lower RMSD is found when $\mathrm{k}_{\mathrm{ve}} / \mathrm{k}_{\mathrm{v}}$ is equal to 0.5 and with the RMSD values of $57.7 \%$, $77.5 \%$ and $34.5 \%$ for locations of SP-13, SP-14 and SP-15 respectively. The erroneous can be contributed by the smear-effect that is not easy to model in the finite element analysis [3]. However, this study is alluding to recommend that the coefficient of permeability for finite element analysis should be one-half of the coefficient of permeability obtained from the laboratory test.

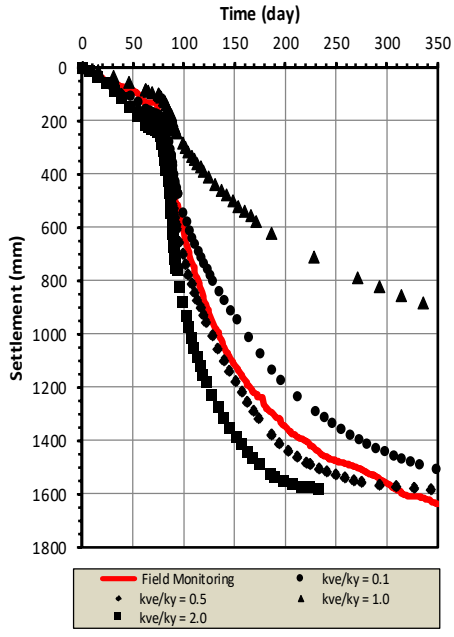

(a)

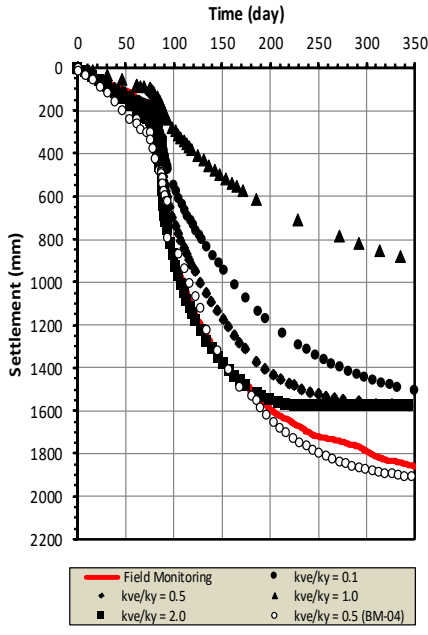

(b)

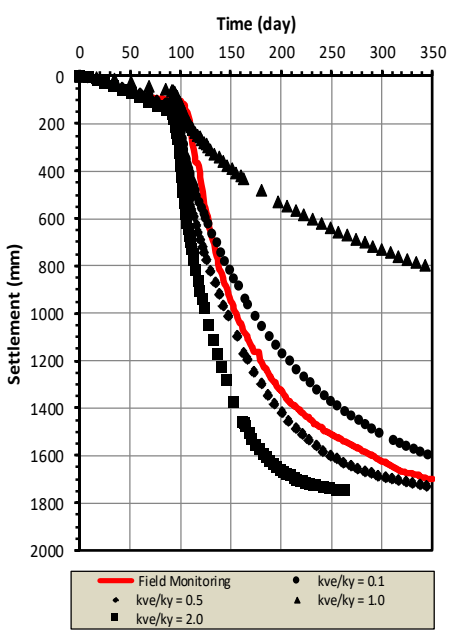

(c)

Fig. 9. Ground settlement curve with time at BM-03 and BM-04 for (a) SP-13 (b) SP-14, (c) SP-15.

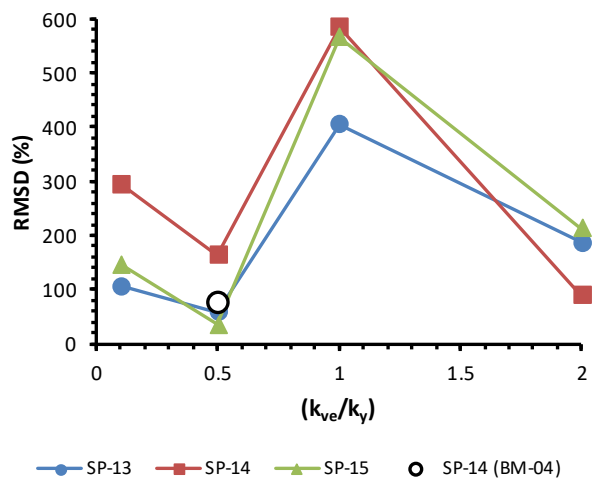

Fig. 10. Root Mean Square Deviation (RMSD) vs permeability ratio.

Table 7. Final settlement prediction results from numerical modelling.

\begin{tabular}{|c|c|c|c|c|c|c|}
\hline \multirow{3}{*}{ Borehole } & \multirow{3}{*}{ SP } & \multicolumn{4}{|c|}{$\begin{array}{l}\text { Final settlement for different } \\
\text { permeability ratios }(\mathrm{mm})\end{array}$} & \multirow{3}{*}{$\begin{array}{c}\text { Field } \\
\text { measurement of } \\
\text { the final } \\
\text { settlement }(\mathrm{mm})\end{array}$} \\
\hline & & \multicolumn{4}{|c|}{$\mathbf{k}_{\mathbf{v e}} / \mathbf{k}_{\mathbf{v}}$} & \\
\hline & & 1 & 0.1 & 0.5 & 2 & \\
\hline \multirow[t]{3}{*}{ BM-03 } & SP-13 & 1580 & 1580 & 1580 & 1580 & 1637 \\
\hline & \multirow{2}{*}{ SP-14 } & \multirow{2}{*}{1575} & \multirow{2}{*}{1575} & 1575 & \multirow{2}{*}{1574} & \multirow{2}{*}{1860} \\
\hline & & & & $1917 *$ & & \\
\hline BM-04 & SP-15 & 1748 & 1742 & 1746 & 1748 & 1701 \\
\hline
\end{tabular}

* the model used soil parameter from borehole BM-04 


\section{Conclusion}

Analytical using Asaoka Method and finite element analysis of the ground settlement of the PVD-improved soft clay has been comparable to the field measurement. Because of the availability of the complete observation data, the estimated final settlement by the Asaoka method shows perfect proximity to the field measurement. The prediction difference is lesser than $1 \%$. Furthermore, the final settlement calculated from the finite element analysis also shows proximity to field measured final settlement with an error of $5 \%$. The ground settlement behaviour calculated from the numerical analysis is closest to the field measured data when the permeability ratio $\left(\mathrm{k}_{\mathrm{ve}} / \mathrm{k}_{\mathrm{v}}\right)$ is equal to 0.5 . The coefficient of permeability plays a crucial role in estimating the consolidation rate and settlement of the soft clayey soil in the numerical analysis. Therefore, the soil parameter plays a significant rule and is very sensitive in the numerical analysis.

This research was supported by Universitas Muhammadiyah Yogyakarta in 2013. The authors wish to thank the Research Center of the Universitas Muhammadiyah Yogyakarta and Wahyu P. Kuswanda, the Director of PT. Teknindo Geosistem Unggul for the support and data provided.

\section{References}

1. J. Saowapakpiboon, D.T. Bergado, S. Hayashi, J.C. Chai, N. Kovittayanon and T.P. de Zwart, Lowland Tech. Int. 10 (1), 42-53 (2008)

2. B. Indraratna, I.W. Redana, Can. Geotech. J., 37, 132-145, (2000)

3. B. Indraratna, I. Sathananthan, C. Bamunawita, S. Balasubramaniam, Theoretical and Numerical Perspectives and Field Observations for the Design and Performance Evaluation of Embankments Constructed on Soft Marine Clay, Ground Improvement-Case Histories Book, in B. Indraratna, J. Ch (Eds.), Vol. 3, pp. 61-106 (2005)

4. D. Russell, Finite Element Analysis of Soil Containing Vertical Drains, Ground Engineering, August 1992, pp. 20-24, (1992)

5. A. Asaoka, Soil Found., 18(4), 87-101 (1978)

6. H. Nawir, D. Apoji, R. Fatimatuzahro, M.D. Pamudji, J. Teknik Sipil, 19, 133-148 (2012)

7. I. Sathananthan, Modelling of Vertical Drains with Smear Installed in Soft Clay, Ph.D Dissertation, School of Civil, Mining, and Environmental Engineering, University of Wollongong, (2005)

8. S. Hansbo, Consolidation of fine-grained soils by prefabricated drains, Proceedings of 10th International Conference on Soil Mechanics and Foundation Engineering, Stockholm, Vol. 3, pp. 677-682. Balkema, Rotterdam, (1981) 